\title{
Synthesis and In Vitro Anti Leishmania amazonensis Biological Screening of Morita-Baylis-Hillman Adducts Prepared from Eugenol, Thymol and Carvacrol
}

\author{
Francisco José Seixas Xavier ${ }^{1}$, Klinger Antonio da Franca Rodrigues ${ }^{2}$, \\ Ramon Guerra de Oliveira ${ }^{1}$, Claudio Gabriel Lima Junior ${ }^{1}$, Juliana da Câmara Rocha ${ }^{3}$, \\ Tatjana Souza Lima Keesen ${ }^{3}$, Marcia Rosa de Oliveira ${ }^{2}$, Fábio Pedrosa Lins Silva ${ }^{1, *}$ \\ and Mário Luiz Araújo de Almeida Vasconcellos 1,* \\ 1 Laboratório de Síntese Orgânica Medicinal da Paraíba (LASOM-PB), Departamento de Química, \\ Universidade Federal da Paraíba, Campus I, João Pessoa, Paraíba CEP 58059-900, Brazil; \\ seicxhas@hotmail.com (F.J.S.X.); ramonoliveirajp@gmail.com (R.G.d.O.); claudio@quimica.ufpb.br (C.G.L.J.) \\ 2 Programa de Pós-graduação em Biologia Molecular and Departamento de Biologia Molecular, \\ Centro de Ciências Exatas and da Natureza, Universidade Federal da Paraíba, João Pessoa, \\ Paraíba CEP 58059-900, Brazil; klinger.antonio@gmail.com (K.A.d.F.R.); mrosajp@gmail.com (M.R.d.O.) \\ 3 Departamento de Biotecnologia, Universidade Federal da Paraíba, Campus I, João Pessoa, \\ Paraíba CEP 58059-900, Brazil; ju_jurocha@hotmail.com (J.d.C.R.); tat.keesen@cbiotec.ufpb.br (T.S.L.K.) \\ * Correspondence: pedrosalinssilva@gmail.com (F.P.L.S.); mlaav@quimica.ufpb.br (M.L.A.d.A.V.); \\ Tel.: +55-083-3216-7589 (F.P.L.S. \& M.L.A.d.A.V.)
}

Academic Editor: Diego Muñoz-Torrero

Received: 11 October 2016; Accepted: 1 November 2016; Published: 8 November 2016

\begin{abstract}
Leishmaniasis represents a series of severe neglected tropical diseases caused by protozoa of the genus Leishmania and is widely distributed around the world. Here, we present the syntheses of Morita-Baylis-Hillman adducts (MBHAs) prepared from eugenol, thymol and carvacrol, and their bioevaluation against promastigotes of Leishmania amazonensis. The new MBHAs are prepared in two steps from essential oils in moderate to good yields and present $\mathrm{IC}_{50}$ values in the range of $22.30-4.71 \mu \mathrm{M}$. Moreover, the selectivity index to the most potent compound is very high (SIrb > 84.92), far better than that of Glucantime ${ }^{\circledR}$ (SIrb 1.39) and amphotericin B (SIrb = 22.34). Conformational analysis were carried out at the M062X//6-31+G(d,p) level of theory to corroborate a hypothesis about the nitroaromatic bioreduction mechanism.
\end{abstract}

Keywords: Morita-Baylis-Hillman adducts; Leishmania amazonensis; eugenol; thymol; carvacrol

\section{Introduction}

Leishmaniasis is considered a set of neglected tropical diseases (NTD) caused by protozoa of the genus Leishmania and is widely distributed around the world [1]. These diseases are classified into three clinical forms: visceral leishmaniasis (VL), cutaneous leishmaniasis (CL) and mucocutaneous leishmaniasis (MCL). The most abundant species in the Americas, which causes general disfigurement of the face (MCL) and leads to patients withdrawing from social life, are Leishmania braziliensis and Leishmania amazonensis [2]. Approximately 500,000 new cases of VL are registered each year and are responsible for the deaths of thousands of people. Six countries, one of which is Brazil, account for $90 \%$ of deaths related to the disease. The World Health Organization (WHO) estimates that approximately one billion people live in areas at risk, and the 0.9-1.3 million new cases are responsible for the deaths of approximately 30,000 people annually [3]. Leishmania spp. is distributed by sandflies, which inject infective promastigotes into the skin of mammalian hosts during a blood meal. To date, there is no leishmaniasis vaccine for humans [4]. Few drug treatment options are available, which are 
lengthy, toxic, and expensive. In some cases, hospitalization is required, leading to discontinuance of treatment when some improvement is observed in the patient [5]. In addition, Leishmania is developing tolerance to the most effective drugs on the market; therefore, the drugs are losing efficiency. Thus, the development of more efficient and cheaper drugs to improve the pharmacological action and the discovery of novel therapeutic targets against trypanosomatids (e.g., Leishmania spp.) are major themes of this field [6].

In the last ten years, our research group has been continuously dedicated to the design, synthesis and biological evaluation of Morita-Baylis-Hillman adducts (MBHAs) as antileishmanial treatments and as treatments against other parasitic NTDs [7]. The Morita-Baylis-Hillman reaction (MBHR, Scheme 1) has been consolidated as an efficient methodology for C-C bond formation [7-9]. Polyfunctional MBHA products are obtained in one step by the MBHR by using nucleophilic catalysis (DABCO is the most common catalyst) under metal-free conditions and may be performed in an aqueous solvent mixture or in a solvent-free medium. MBHR is now classified as an important green reaction in organic syntheses [7].

$$
\begin{aligned}
& \underset{\mathrm{R}}{\stackrel{\mathrm{X}}{\mathrm{X}}} \mathrm{H}+\pi^{\text {EAG }} \underset{\text { i.e. } \mathrm{NR}_{3}}{\frac{\text { nucleophilic catalyst }}{\longrightarrow}} \\
& \mathrm{R}=\text { alkyl, aryl, heteroaryl } \\
& \mathrm{X}=\mathrm{O}, \mathrm{NCO}_{2} \mathrm{R}, \mathrm{NTs}, \mathrm{NSO}_{2} \mathrm{Ph} \text {. } \\
& \mathrm{EAG}=\mathrm{COR}, \mathrm{CHO}, \mathrm{CN}, \mathrm{CO}_{2} \mathrm{R}
\end{aligned}
$$<smiles>[R]C([Y1])C(=C)C([R])(C)C</smiles>

MBHA

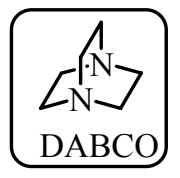

Scheme 1. General Morita-Baylis-Hillman reaction. EAG = Electron attractor group.

In 2011, we reported that MBHA 1 (a chalcone-like compound), designed from the molecular hybridization [10] of the analgesic methyl salicylate (2) and the MBHA 3 (Scheme 2), presented a lower $\mathrm{IC}_{50}$ in a congener series of compounds and was shown to be an efficient molecular hybrid and a promising leishmanicidal drug.
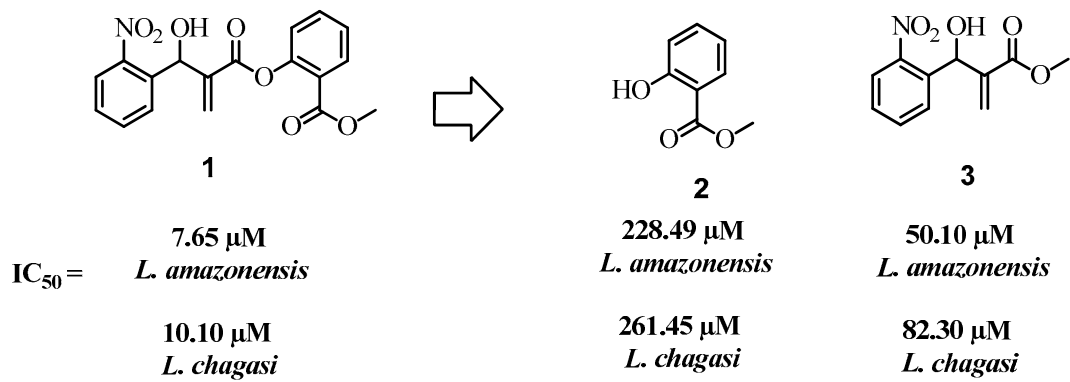

Scheme 2. Molecular hybridization between MBHA 3 and methyl salicylate $\mathbf{2}$ for the design of hybrid $\mathbf{1}$.

In connection with our interest in discovering new compounds with efficient leishmanicidal properties [7,11-15], we present here the design, syntheses, and in vitro leishmanicidal evaluations against L. amazonensis of nine new $o^{-}, m$ - and $p$-nitro MBHA hybrids based on the synergistic biological proprieties of the abundant and inexpensive essential oil ingredients eugenol (4), thymol (5) and carvacrol (6) (Figure 1). It is important to note that eugenol (4) is an analgesic with leishmanicidal [16] and several others biological activities [17,18]. Thymol (5) and carvacrol (6) present analgesic and leishmanicidal activities [19]. In Figure 1, we also present MBHAs 16, 17 and 3, which were also biologically evaluated to compare motifs [15]. A conformational DFT study is presented to corroborate our proposed mechanism of the reduction of nitroaryl derivatives concerning these nitro-MBHAs [19]. 


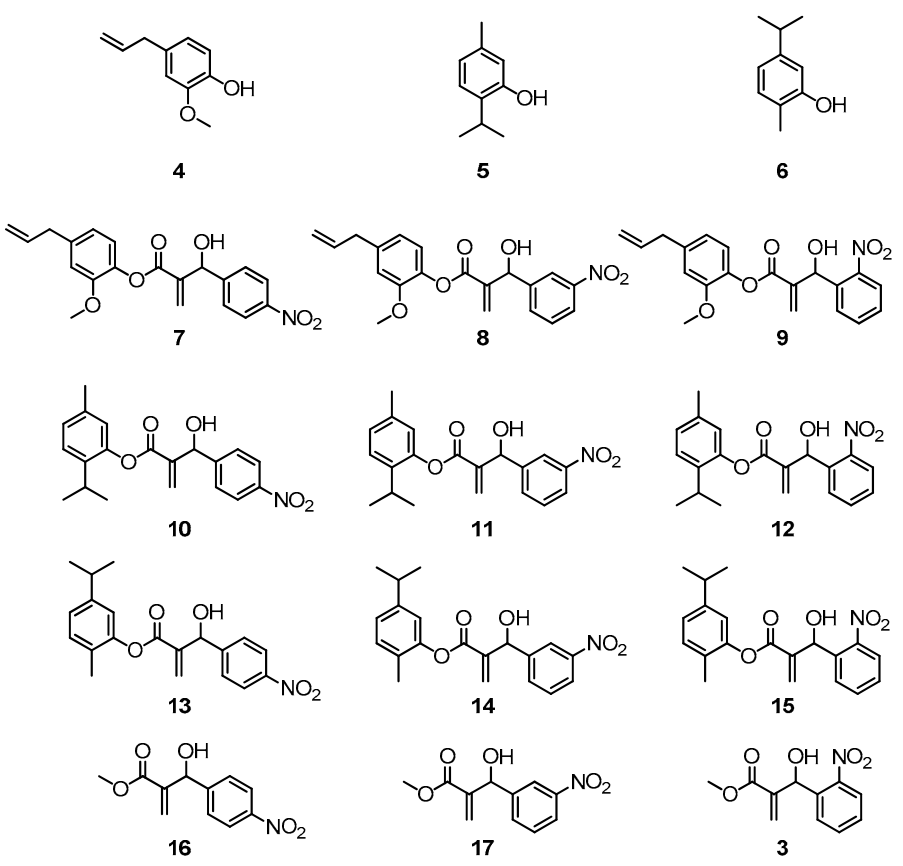

Figure 1. The MBHA hybrids synthetized, biologically evaluated and conformationally studied in this paper and eugenol (4), thymol (5), and carvacrol (6). Compounds 7-9 are hybrids derived from eugenol; compounds 10-12 are hybrids made from thymol. Compounds 13-15 are hybrids of carvacrol. Compounds 16, 17 and 3 are MBHAs.

\section{Results and Discussion}

The new acrylates 18-20 and hybrids 7-15 (Figure 1) were synthesized according to Scheme 3. Eugenol, thymol and carvacrol acrylate 18-20 were prepared by the respective reactions with DCC and DMAP (catalytic) at $0{ }^{\circ} \mathrm{C}$ in dry dichloromethane (Scheme 3). For the synthesis of hybrids 7-15, acetonitrile was used without drying, however, we observed hydrolysis reactions of the hybrids leading to the products at low yields ( $<40 \%$ yields). To optimize the reaction yields, dry acetonitrile was used as a solvent at room temperature to thus obtain hybrids 7-15 in moderate to good yields (Scheme 3).
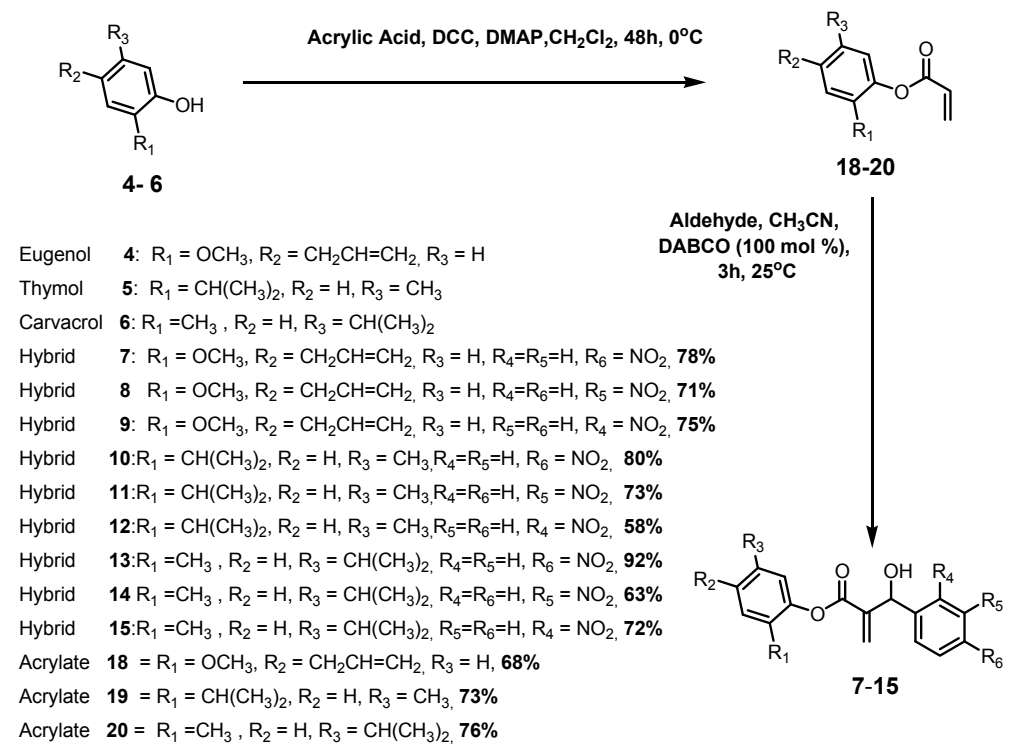

Scheme 3. Reagents, conditions, rates, and yields (\%) of our preparations of new compounds 7-15 and 18-20. 
The antileishmanial activities against promastigotes of L. amazonensis of compounds 3-17 are presented in Table 1. Some results in this Table should be highlighted here.

Table 1. The antileishmanial activities against promastigotes of L. amazonensis. Values represent the average $\mathrm{IC}_{50}$ calculated in three independent experiments \pm standard error of the mean. For this calculation, we used the probabilistic regression models with SPSS 13.0 software. SIrb (selectivity index on red blood cell) $=\mathrm{HC}_{50} / \mathrm{IC}_{50}$.

\begin{tabular}{cccccc}
\hline Entry & Compounds & IC $_{\mathbf{5 0}}(\boldsymbol{\mu M})$ & HC $_{\mathbf{5 0}}(\boldsymbol{\mu M})$ & SIrb & miLogP \\
\hline 1 & $\mathbf{4}$ & $77.15 \pm 1.77$ & $>400$ & $>5.18$ & 2.10 \\
2 & $\mathbf{7}$ & $8.75 \pm 0.44$ & $>400$ & $>45.71$ & 3.05 \\
3 & $\mathbf{8}$ & $10.49 \pm 0.52$ & $>400$ & $>38.13$ & 3.02 \\
4 & $\mathbf{9}$ & $4.71 \pm 0.24$ & $>400$ & $>84.92$ & 3.00 \\
5 & $\mathbf{5}$ & $115.12 \pm 5.77$ & - & - & 3.34 \\
6 & $\mathbf{1 0}$ & $11.40 \pm 0.57$ & - & - & 4.05 \\
7 & $\mathbf{1 1}$ & $10.56 \pm 0.53$ & - & - & 4.03 \\
8 & $\mathbf{1 2}$ & $5.91 \pm 0.30$ & - & - & 4.00 \\
9 & $\mathbf{6}$ & $138.11 \pm 6.91$ & - & - & 3.81 \\
11 & $\mathbf{1 3}$ & $18.08 \pm 0.90$ & - & - & 4.52 \\
12 & $\mathbf{1 4}$ & $22.30 \pm 1.12$ & - & - & 4.50 \\
13 & $\mathbf{1 5}$ & $13.60 \pm 0.68$ & - & - & 4.47 \\
14 & $\mathbf{1 6}$ & $15.77 \pm 0.79$ & $>400$ & $>25.36$ & 1.53 \\
15 & $\mathbf{1 7}$ & $22.38 \pm 1.12$ & $>400$ & $>17.87$ & 1.50 \\
16 & $\mathbf{3}$ & $12.06 \pm 0.60$ & $>400$ & $>33.16$ & 1.48 \\
17 & Glucantime & $1633.49 \pm 437.29$ & 1175.02 & 1.39 & -2.68 \\
18 & AmphotericinB & $0.52 \pm 0.03$ & 11.61 & 22.34 & -2.49 \\
\hline
\end{tabular}

We can observe that eugenol (4, Entry 1$)$ exhibits greater leishmanicidal activity than the other essential oils thymol (5, Entry 5) and carvacrol (6, Entry 9). All hybrids derived from eugenol (compounds 7-9, Entries 2-4), thymol (10-12, Entries 6-8) and carvacrol (13-15, Entries 11-13) exhibit higher antileishmanial activity than the corresponding essential oils ingredients. The hybrids of eugenol (compounds 7-9, Entries 2-4) showed lower $\mathrm{IC}_{50}$ values than the other series. Another very important dataset shown in Table 1, which is in agreement with previously obtained data by our research group [7], indicates that the nitrated MBHAs presenting an ortho nitro group on the aromatic ring are more bioactive against promastigotes of L. amazonensis than the corresponding meta and para nitroaryl isomers. Several nitro aromatics are used as anti-infective agents, e.g., drugs to treat parasitic infections. The biological activity of the nitro compounds is connected to a nitro group reduction that generates $\mathrm{RNO}^{-\bullet}$ or more reduced intermediates (Scheme 4) [19].

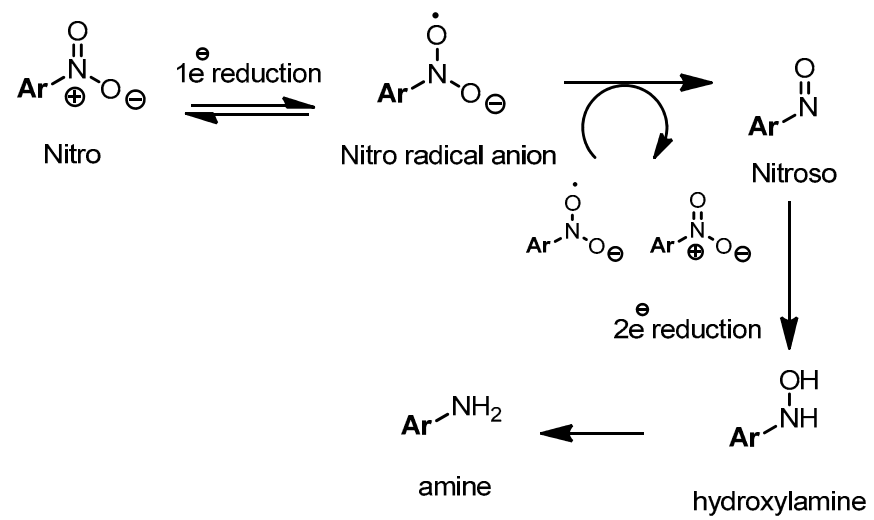

Scheme 4. General scheme of the $2 \mathrm{e}^{-}$nitro aromatic reduction $(\mathrm{Ar}=$ aromatic group) 
Currently, the exact mechanism of action of MBHAs against Leishmania targets is not known. To propose a biological mechanism of action for these new nitroaryl hybrids and to elucidate the reasons behind the higher bioactivity of the ortho nitro regioisomer compared to the meta and para regioisomers, the calculation of the more stable conformation of $\mathbf{7}$ and $\mathbf{9}$ in a simulated aqueous medium were performed. These geometries are shown in Figure 2.

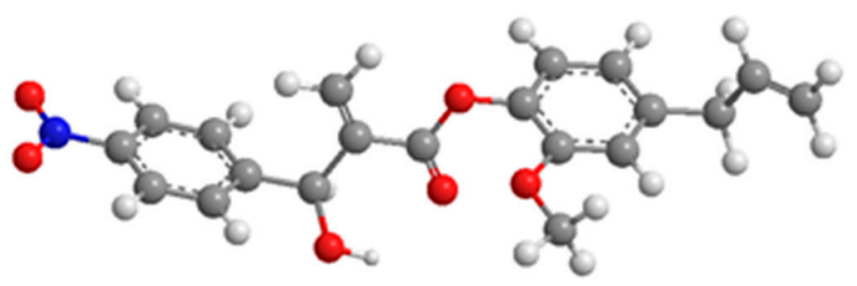

7

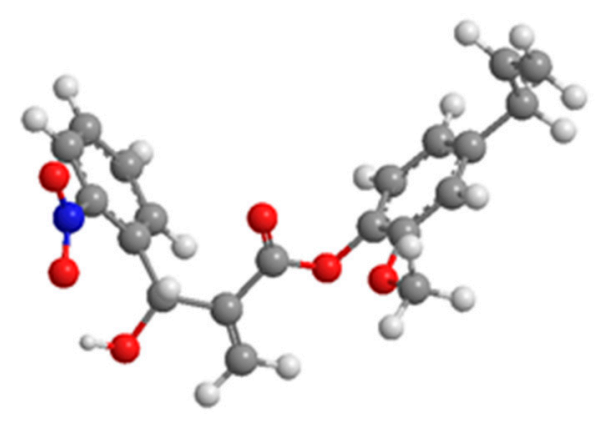

9

Figure 2. Conformational minima of hybrids 7 and 9 obtained by M062X//6-31+G(d,p) in implicit water simulation as the level of the calculations.

In previous electrochemical studies by cyclic voltammetry of the corresponding adducts 16, 17 and 3 (Figure 1), it was observed that ortho aryl 3 is more easily reduced to the corresponding anion radical $\left(\mathrm{ArNO}_{2}{ }^{-}\right)$of the isomers $\mathbf{1 6}$ and $\mathbf{1 7}[20,21]$. It was proposed by QTAIM calculations that the dihedral deviation of the $\mathrm{NO}_{2}$ moiety in ortho aryl 9 with the aromatic ring is caused by the intramolecular hydrogen bonding ( $\mathrm{IHB}$ ) of the seven-member grouping ( $\mathrm{HO}-\mathrm{O}-\mathrm{N}-\mathrm{O}, \mathrm{IHB}=2.104 \AA$ ) [22], which is responsible for the highest electron affinity of this nitrogen. These data are accepted as the reason behind the ease of the biological reduction the ortho nitro compounds related to their greater leishmanicidal activity [21]. We can note from Figure 2 that, in the hybrid 7, the nitro group is nearly coplanar with an aromatic ring (dihedral angle $\mathrm{NO}_{2}-\mathrm{Ar}=1.7^{\circ}$ ), which is very different from the observation of hybrid 9 (dihedral angle $\mathrm{NO}_{2}-\mathrm{Ar}=31.0^{\circ}$ ). Thus, the radical intermediates from ortho MBHA could present higher lifetimes than those of the para nitro regioisomer in cytoplasmic medium, increasing the cleavage of the nuclear membrane of protozoa [21].

\section{Materials and Methods}

\subsection{Experimental Chemistry}

General

All commercially available reagents and solvents were obtained from the provider Sigma-Aldrich ${ }^{\circledR}$ (St. Louis, MO, USA) and used without further purification. Reactions were monitored by TLC using Silica gel 60 UV254 pre-coated silica gel plates (Macherey-Nagel, Bethlehem, PA, USA) and detection was performed using a UV lamp. Flash column chromatography was performed on 300-400 mesh silica gels. Organic layers were dried over anhydrous $\mathrm{MgSO}_{4}$ or $\mathrm{Na}_{2} \mathrm{SO}_{4}$ prior to evaporation using a rotary evaporator. ${ }^{1} \mathrm{H}-\mathrm{NMR}$ and ${ }^{13} \mathrm{C}-\mathrm{NMR}$ spectra were recorded using a Mercury Spectra AC 20 
spectrometer (200 MHz for ${ }^{1} \mathrm{H}, 50 \mathrm{MHz}$ for ${ }^{13} \mathrm{C}$, Varian, (Varian, Palo Alto, CA, USA). Chemical shifts were reported relative to internal tetramethylsilane $(\delta 0.00 \mathrm{ppm})$ for ${ }^{1} \mathrm{H}$, using $\mathrm{CDCl}_{3}$ as the solvent. FTIR spectra were recorded using a model IRPrestige-21 spectrophotometer (Shimadzu, Kyoto, Japan) in $\mathrm{KBr}$ pellets. The high-resolution mass spectrometry (HRMS) of new compounds 7-15 (Figure 1) was performed using a Q-Tof quadrupole/orthogonal instrument (Waters, Milford, MA, USA) in positive and negative mode.

\subsection{General Procedure for Esterification of Eugenol (4), Thymol (5) and Carvacrol (6) with Acrylic Acid; Preparation of Compounds 18-20}

Eugenol $(3,1.640 \mathrm{~g}, 10.0 \mathrm{mmol})$, thymol $(4,1.500 \mathrm{~g}, 10.0 \mathrm{mmol})$ or carvacrol $(5,1.500 \mathrm{~g}, 10.0 \mathrm{mmol})$ and dry dichloromethane $(10.0 \mathrm{~mL})$ were added in a bottle flask. After homogenization in an ice-bath and magnetic stirring, DCC $(2.060 \mathrm{~g}, 10.0 \mathrm{mmol})$ and DMAP $(0.122 \mathrm{~g}, 1 \mathrm{mmol})$ were added. The reaction was monitored by TL chromatography for $48 \mathrm{~h}$. Filtration on a separating funnel was performed. Water was added and the reaction mixture was extracted with dichloromethane $(30.0 \mathrm{~mL} \times 2)$. The organic phase was dried over anhydrous $\mathrm{Na}_{2} \mathrm{SO}_{4}$ and concentrated under reduced pressure using a rotary evaporator. Purification was performed using a chromatographic column containing $30.0 \mathrm{~g}$ of flash silica gel, using $100.0 \mathrm{~mL}$ of hexane as eluent followed by a mixture of $300 \mathrm{~mL}$ ethyl acetate/hexane $(30 \%)$. The fractions were collected, and the solvent was evaporated from the obtained product using a rotary evaporator. The expected products were colorless, somewhat viscous oils and solid at temperatures below $0{ }^{\circ} \mathrm{C}$.

\subsubsection{4-Allyl-2-methoxyphenyl acrylate (18)}

$68 \%$ yield; FTIR KBr: $1745 \mathrm{~cm}^{-1}$ (C=O); $1637 \mathrm{~cm}^{-1}$ (C=C); 1602 (C=C); $1035 \mathrm{~cm}^{-1}$ (C-O-C). ${ }^{1} \mathrm{H}-\mathrm{NMR}$ $\delta$ (ppm): 6.98 (d, $J=7.8 \mathrm{~Hz}, 1 \mathrm{H}, \mathrm{H}-\mathrm{Ar}) ; 6.84-6.73(\mathrm{~m}, 2 \mathrm{H}, \mathrm{H}-\mathrm{Ar}) ; 6.60\left(\mathrm{dd}, J=17.3,1.6 \mathrm{~Hz}, 1 \mathrm{H}, \mathrm{CH}_{2}=\mathrm{CH}\right)$; $6.33\left(\mathrm{dd}, J=17.3,10.3 \mathrm{~Hz}, 1 \mathrm{H}, \mathrm{CH}_{2}=\mathrm{CH}\right) ; 6.06-5.84\left(\mathrm{~m}, 2 \mathrm{H}, \mathrm{CH}=\mathrm{CH}_{2}\right) ; 5.17-5.03\left(\mathrm{~m}, 2 \mathrm{H}, \mathrm{CH}_{2}=\mathrm{CH}\right)$; 3.79 (s, $\left.3 \mathrm{H}, \mathrm{CH}_{3} \mathrm{OPh}\right) ; 3.37\left(\mathrm{~d}, J=6.7 \mathrm{~Hz}, 2 \mathrm{H}, \mathrm{CH}_{2} \mathrm{Ph}\right) .{ }^{13} \mathrm{C}-\mathrm{NMR} \delta(\mathrm{ppm}): 164.28\left(\mathrm{C}_{3}\right) ; 150.91\left(\mathrm{C}_{7}\right)$; $139.07\left(\mathrm{C}_{9}\right)$; $137.67\left(\mathrm{C}_{4}\right)$; $137.04\left(\mathrm{C}_{1}\right) ; 132.46\left(\mathrm{C}_{10}\right) ; 127.64\left(\mathrm{C}_{2}\right) ; 122.50\left(\mathrm{C}_{5}\right) ; 120.68\left(\mathrm{C}_{6}\right) ; 116.18\left(\mathrm{C}_{12}\right)$; $112.75\left(\mathrm{C}_{8}\right) ; 55.81\left(\mathrm{C}_{13}\right) ; 40.10\left(\mathrm{C}_{11}\right)$.

\subsubsection{2-Isopropyl-5-methylphenyl acrylate (19)}

73\% yield; FTIR KBr: $1743 \mathrm{~cm}^{-1}(\mathrm{C}=\mathrm{O}) ; 1622 \mathrm{~cm}^{-1}(\mathrm{C}=\mathrm{C}) .{ }^{1} \mathrm{H}-\mathrm{NMR} \delta(\mathrm{ppm}): 7.19(\mathrm{~d}, \mathrm{~J}=7.9 \mathrm{~Hz}, 1 \mathrm{H}$, $\mathrm{H}-\mathrm{Ar}) ; 7.00(\mathrm{~d}, J=8,9 \mathrm{~Hz}, 1 \mathrm{H}, \mathrm{H}-\mathrm{Ar}) ;) 6.69(\mathrm{~s}, 1 \mathrm{H}, \mathrm{H}-\mathrm{Ar}) ; 6.57\left(\mathrm{dd}, J=17.2,1.4 \mathrm{~Hz}, 1 \mathrm{H}, \mathrm{CH}_{2}=\mathrm{CH}\right) ; 6.33$ $\left(\mathrm{dd}, J=17.3,10.3 \mathrm{~Hz}, 1 \mathrm{H}, \mathrm{CH}=\mathrm{CH}_{2}\right) ; 5.97\left(\mathrm{~d}, J=10.3 \mathrm{~Hz}, 1 \mathrm{H}, \mathrm{CH}_{2}=\mathrm{CH}\right) ; 2.98-2.75\left(\mathrm{~m}, 1 \mathrm{H}, \mathrm{HC}-\left(\mathrm{CH}_{3}\right)_{2}\right)$; $2.13\left(\mathrm{~s}, 3 \mathrm{H}, \mathrm{H}_{3} \mathrm{C}-\mathrm{Ph}\right), 1.23\left(\mathrm{~d}, J=6.9 \mathrm{~Hz}, 6 \mathrm{H},\left(\mathrm{CH}_{3}\right)_{2}-\mathrm{CH}\right) .{ }^{13} \mathrm{C}-\mathrm{NMR} \delta$ (ppm): 164.41 (C3); 149.12 (C6); $148.10\left(\mathrm{C}_{4}\right) ; 132.43\left(\mathrm{C}_{1}\right) ; 130.93\left(\mathrm{C}_{8}\right) ; 127.86\left(\mathrm{C}_{2}\right) ; 127.23\left(\mathrm{C}_{9}\right) ; 124.24\left(\mathrm{C}_{7}\right) ; 119.73\left(\mathrm{C}_{5}\right) ; 33.60,\left(\mathrm{C}_{11}\right) ; 23.95$ $\left(\mathrm{C}_{12 / 12^{\prime}}\right) ; 15.80\left(\mathrm{C}_{10}\right)$.

\subsubsection{5-Isopropyl-2-methylphenyl acrylate (20)}

$76 \%$ yield; FTIR KBr: $1743 \mathrm{~cm}^{-1}(\mathrm{C}=\mathrm{O}) ; 1635 \mathrm{~cm}^{-1}(\mathrm{C}=\mathrm{C}) ; 1622 \mathrm{~cm}^{-1}(\mathrm{C}=\mathrm{C}) .{ }^{1} \mathrm{H}-\mathrm{NMR} \delta$ (ppm): 7.08 (d, J = 7.8 Hz, 1H, H-Ar); 6.97 (d, J = 7.8 Hz, 1H, H-Ar);) 6.69 (s, 1H, H-Ar); 6.57 (dd, J = 17.2, $1.4 \mathrm{~Hz}$, $\left.1 \mathrm{H}, \mathrm{CH}_{2}=\mathrm{CH}\right) ; 6.33\left(\mathrm{dd}, J=17.3,10.3 \mathrm{~Hz}, 1 \mathrm{H}, \mathrm{CH}=\mathrm{CH}_{2}\right) ; 5.97\left(\mathrm{~d}, J=10.3 \mathrm{~Hz}, 1 \mathrm{H}, \mathrm{CH}_{2}=\mathrm{CH}\right) ; 2.98-2.75$ $\left(\mathrm{m}, 1 \mathrm{H}, \mathrm{HC}-\left(\mathrm{CH}_{3}\right)_{2}\right) ; 2.13\left(\mathrm{~s}, 3 \mathrm{H}, \mathrm{H}_{3} \mathrm{C}-\mathrm{Ph}\right), 1.23\left(\mathrm{~d}, J=6.9 \mathrm{~Hz}, 6 \mathrm{H},\left(\mathrm{CH}_{3}\right)_{2}-\mathrm{CH}\right) .{ }^{13} \mathrm{C}-\mathrm{NMR} \delta(\mathrm{ppm})$ : $164.41\left(\mathrm{C}_{3}\right) ; 149.12\left(\mathrm{C}_{6}\right) ; 148.10\left(\mathrm{C}_{4}\right) ; 132.43\left(\mathrm{C}_{1}\right) ; 130.93\left(\mathrm{C}_{8}\right) ; 127.86\left(\mathrm{C}_{2}\right) ; 127.23\left(\mathrm{C}_{9}\right) ; 124.24\left(\mathrm{C}_{7}\right) ; 119.73$ $\left(\mathrm{C}_{5}\right) ; 33.60,\left(\mathrm{C}_{11}\right) ; 23.95\left(\mathrm{C}_{12 \mathrm{e} 12^{\prime}}\right) ; 15.80\left(\mathrm{C}_{10}\right)$.

\subsection{General Synthesis of the MBHAs $\mathbf{1 6}, \mathbf{1 7}$ and $\mathbf{3}$}

The compounds 16, 17 and 3 synthesized in this work are not new and were characterized using ${ }^{1} \mathrm{H}-\mathrm{NMR}$ and ${ }^{13} \mathrm{C}-\mathrm{NMR}$ for comparison with the compounds described in the literature [14]. Reactions were carried out using the corresponding aldehydes $(1 \mathrm{mmol})$, methyl acrylate $(0.5 \mathrm{~mL})$ and of DABCO 
$(1 \mathrm{mmol})$ at $0{ }^{\circ} \mathrm{C}$. After some time, the reaction media was directly filtered through silica gel using EtOAc-hexane (2:8) as the solvent, and the reaction products were concentrated under reduced pressure. The products were then ready for biological evaluations without the need of further purification.

\subsubsection{2-[Hydroxy(4-nitrophenyl)methyl]propanoate (16)}

$85 \%$ yield; ${ }^{1} \mathrm{H}-\mathrm{NMR} \delta(\mathrm{ppm}): \mathrm{d}, 8.16(\mathrm{~d}, 2 \mathrm{H}, J=8.8 \mathrm{~Hz}), 7.54(\mathrm{~d}, 2 \mathrm{H}, J=8.4 \mathrm{~Hz}), 6.36(\mathrm{~s}, 1 \mathrm{H}), 5.86(\mathrm{~s}, 1 \mathrm{H})$, $5.60(\mathrm{~d}, J=5.8 \mathrm{~Hz}, 1 \mathrm{H}), 3.71(\mathrm{~s}, 3 \mathrm{H}), 3.41(\mathrm{~d}, J=5.8 \mathrm{~Hz}, 1 \mathrm{H}) .{ }^{13} \mathrm{C}-\mathrm{NMR} \delta(\mathrm{ppm}): 52.2(1 \mathrm{C}), 72.6(1 \mathrm{C})$, 123.5 (1C), 137.2 (1C), 127.3 (1C), 140.8 (1C), 147.3 (1C), 148.5 (1C), 166.3 (1C).

\subsubsection{2-[Hydroxy(3-nitrophenyl)methyl]propanoate (17)}

98\% yield; ${ }^{1} \mathrm{H}-\mathrm{NMR} \delta(\mathrm{ppm}): \mathrm{d}, 8.22(\mathrm{t}, J=1.8 \mathrm{~Hz}, 1 \mathrm{H}) ; 8.08-8.13(\mathrm{~m}, 1 \mathrm{H}) ; 7.69-7.73(\mathrm{~m}, 1 \mathrm{H}) ; 7.50$ $(\mathrm{t}, J=8 \mathrm{~Hz}, 1 \mathrm{H}) ; 6.38(\mathrm{~s}, 1 \mathrm{H}) ; 5.89(\mathrm{~s}, 1 \mathrm{H}) ; 5.60(\mathrm{~d}, J=4.4 \mathrm{~Hz}, 1 \mathrm{H}) ; 3.70(\mathrm{~s}, 3 \mathrm{H}) ; 3.46(\mathrm{~d}, J=5.4 \mathrm{~Hz}, 1 \mathrm{H})$. ${ }^{13} \mathrm{C}-\mathrm{NMR} \delta$ (ppm): 52.2 (1C), 72.5 (1C), 121.5 (1C), 122.7 (1C), 127.2 (1C), 129.3 (1C), 132.7 (1C), 140.9 (1C), $143.5(1 \mathrm{C}), 148.2(1 \mathrm{C}), 166.3(1 \mathrm{C})$.

\subsubsection{2-[Hydroxy(2-nitrophenyl)methyl]propanoate (3)}

92\% yield; ${ }^{1} \mathrm{H}-\mathrm{NMR} \delta(\mathrm{ppm}): \mathrm{d}, 7.92(\mathrm{dd}, J=8.2 / 1.2 \mathrm{~Hz}, 1 \mathrm{H}) ; 7.73(\mathrm{dd}, J=7.8 / 1.8 \mathrm{~Hz}, 1 \mathrm{H}) ; 7.62(\mathrm{ddd}$, $J=7.8 / 1.2 / 1.0 \mathrm{~Hz}, 1 \mathrm{H}) ; 7.43(\mathrm{ddd}, J=8.0 / 1.6 / 1.6 \mathrm{~Hz}, 1 \mathrm{H}) ; 6.38(\mathrm{~s}, 1 \mathrm{H}) ; 5.89(\mathrm{~d}, 1 \mathrm{H}) ; 5.60(\mathrm{~d}, J=4.4 \mathrm{~Hz}$, $1 \mathrm{~Hz}) ; 3.70(\mathrm{~s}, 3 \mathrm{H}) ; 3.60(\mathrm{~d}, J=5.4 \mathrm{~Hz}, 1 \mathrm{H}) .{ }^{13} \mathrm{C}-\mathrm{NMR} \delta(\mathrm{ppm}): 52.20$ (1C), 67.56 (1C), 124.55 (1C), 126.48 (1C), 128.67 (C), 128.67 (C) 133.47 (1C), 136.05 (1C), 140.65 (1C), 148.32 (1C), 166.39 (1C).

\subsection{General Synthesis of the Hybrids $\mathbf{7 - 1 5}$}

To a $25.0 \mathrm{~mL}$ flask, acrylate $\mathbf{1 8}, \mathbf{1 9}$ or $\mathbf{2 0}(0.5 \mathrm{mmol})$, the corresponding nitro-substituted aldehyde $(0.6 \mathrm{mmol})$, and dry acetonitrile $(1.0 \mathrm{~mL})$ were added. To the resulting solution DABCO $(0.5 \mathrm{mmol})$ was added. The reaction mixture was stirred at room temperature and monitored by TLC for $3 \mathrm{~h}$. The purified product was obtained by using $6.0 \mathrm{~g}$ of silica and $10.0 \mathrm{~mL}$ of acetonitrile to form a dispersion and added to a chromatographic column containing $30.0 \mathrm{~g}$ of flash silica gel. A mixture

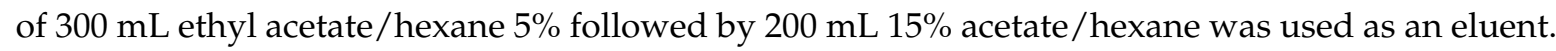
The fractions were separated and transferred to a rotary evaporator. The respective products were yellowish viscous oils at ambient temperature. All spectra are available in the Supplementary information.

\subsubsection{4-Allyl-2-methoxyphenyl 2-(hydroxy(4-nitrophenyl)methyl)acrylate (7)}

$78 \%$ yield; FTIR: $3450 \mathrm{~cm}^{-1}(\mathrm{O}-\mathrm{H}) ; 1735 \mathrm{~cm}^{-1}(\mathrm{C}=\mathrm{O}) ; 1637 \mathrm{~cm}^{-1}(\mathrm{C}=\mathrm{C}) ; 1602 \mathrm{~cm}^{-1}(\mathrm{C}=\mathrm{C}) ; 1531$ and $1350 \mathrm{~cm}^{-1}\left(\mathrm{R}-\mathrm{NO}_{2}\right), 1035 \mathrm{~cm}^{-1}$ (C-O-C). ${ }^{1} \mathrm{H}-\mathrm{NMR} \delta(\mathrm{ppm}): 8.21$ (d, J = $\left.8.8 \mathrm{~Hz}, 2 \mathrm{H}, \mathrm{H}-\mathrm{Ar}\right) ; 7.63(\mathrm{~d}$, $J=8.8 \mathrm{~Hz}, 2 \mathrm{H}, \mathrm{H}-\mathrm{Ar}) ; 6.95-6.89$ (m, 1H, H-Ar); 6.81-6.73 (m, 2H, H-Ar); 6.64 (s, 1H, H-C-OH); 6.02 (d, $\left.J=7.9 \mathrm{~Hz}, 1 \mathrm{H}, \mathrm{CH}_{2}=\mathrm{C}\right) ; 5.96-5.70\left(\mathrm{~m}, 2 \mathrm{H}, \mathrm{CH}=\mathrm{CH}_{2}\right.$ and $\left.\mathrm{CH}_{2}=\mathrm{C}\right) ; 5.16-5.03\left(\mathrm{~m}, 2 \mathrm{H}, \mathrm{CH}_{2}=\mathrm{CH}\right) ; 3.72(\mathrm{~s}$, $\left.3 \mathrm{H}, \mathrm{CH}_{3} \mathrm{OPh}\right) ; 3.40\left(\mathrm{t}, J=13.3 \mathrm{~Hz}, 3 \mathrm{H}, \mathrm{CH}_{2} \mathrm{Ph}\right.$ and HO-C). ${ }^{13} \mathrm{C}-\mathrm{NMR} \delta(\mathrm{ppm}): 168.81\left(\mathrm{C}_{8}\right) ; 155.16\left(\mathrm{C}_{14}\right)$; $153.19\left(\mathrm{C}_{4}\right) ; 152.16\left(\mathrm{C}_{3}\right) ; 145.44\left(\mathrm{C}_{6}\right) ; 144.22\left(\mathrm{C}_{12}\right) ; 141.95\left(\mathrm{C}_{9}\right) ; 141.56\left(\mathrm{C}_{16}\right) ; 133.51\left(\mathrm{C}_{7}\right) ; 132.24\left(\mathrm{C} \mathrm{e}^{\prime}\right)$; $128.29\left(\mathrm{C} 2 \mathrm{e} 2^{\prime}\right) ; 127.01\left(\mathrm{C}_{10}\right) ; 125.46\left(\mathrm{C}_{11}\right) ; 121.03\left(\mathrm{C}_{17}\right) ; 117.37\left(\mathrm{C}_{13}\right) ; 77.33\left(\mathrm{C}_{5}\right) ; 60.45\left(\mathrm{C}_{18}\right) ; 44.78\left(\mathrm{C}_{15}\right)$. HRMS (TOF MS ES-) calculated for $\mathrm{C}_{20} \mathrm{H}_{19} \mathrm{NO}_{6}: 369.3700[\mathrm{M}+\mathrm{H}]^{+}$; found: 370.1298 .

\subsubsection{4-Allyl-2-methoxyphenyl-2-(hydroxy(3-nitrophenyl)methyl)acrylate (8)}

$71 \%$ yield; FTIR: $3450 \mathrm{~cm}^{-1}(\mathrm{O}-\mathrm{H}) ; 1735 \mathrm{~cm}^{-1}(\mathrm{C}=\mathrm{O}) ; 1637 \mathrm{~cm}^{-1}(\mathrm{C}=\mathrm{C}) ; 1602 \mathrm{~cm}^{-1}(\mathrm{C}=\mathrm{C}) ; 1531$ and $1350 \mathrm{~cm}^{-1}\left(\mathrm{R}_{-N O}\right), 1035 \mathrm{~cm}^{-1}$ (C-O-C). ${ }^{1} \mathrm{H}-\mathrm{NMR} \delta$ (ppm): 8.33 (s, 1H, H-Ar); 8.17 (d, J = 7,0 Hz, $1 \mathrm{H}$, H-Ar); $7.80(\mathrm{~d}, J=8.2 \mathrm{~Hz}, 1 \mathrm{H}, \mathrm{H}-\mathrm{Ar}) ; 7.54(\mathrm{t}, J=7.9 \mathrm{~Hz}, 1 \mathrm{H}, \mathrm{H}-\mathrm{Ar}) ; 6.93(\mathrm{~d}, J=8.6 \mathrm{~Hz}, 1 \mathrm{H}, \mathrm{H}-\mathrm{Ar}) ; 6.75$ (d, J = 7.3 Hz, 2H, H-Ar); 6.66 (s, 1H, H-C-OH); $6.03\left(\mathrm{~s}, 1 \mathrm{H}, \mathrm{CH}_{2}=\mathrm{C}\right) ; 5.75-5.95\left(\mathrm{~m}, 2 \mathrm{H}, \mathrm{CH}=\mathrm{CH}_{2}\right.$ and $\left.\mathrm{CH}_{2}=\mathrm{C}\right) ; 5.14-5.04\left(\mathrm{~m}, 2 \mathrm{H}, \mathrm{CH}_{2}=\mathrm{CH}\right) ; 3.72\left(\mathrm{~s}, 3 \mathrm{H}, \mathrm{CH}_{3} \mathrm{OPh}\right) ; 3.36\left(\mathrm{~d}, J=6.7 \mathrm{~Hz}, 3 \mathrm{H}, \mathrm{CH}_{2} \mathrm{Ph}\right.$ and $\left.\mathrm{HO}-\mathrm{C}\right)$. ${ }^{13} \mathrm{C}-\mathrm{NMR} \delta(\mathrm{ppm}): 164.84\left(\mathrm{C}_{10}\right) ; 151.22\left(\mathrm{C}_{16}\right) ; 149.09\left(\mathrm{C}_{4}\right) ; 144.23\left(\mathrm{C}_{6}\right) ; 141.43\left(\mathrm{C}_{9}\right) ; 140.21\left(\mathrm{C}_{14}\right) ; 138.02$ $\left(\mathrm{C}_{11}\right) ; 137.63\left(\mathrm{C}_{18}\right) ; 133.62\left(\mathrm{C}_{1}\right) ; 130.09\left(\mathrm{C}_{2}\right) ; 129.58\left(\mathrm{C}_{8}\right) ; 123.55\left(\mathrm{C}_{5}\right) ; 123.06\left(\mathrm{C}_{3}\right) ; 122.45\left(\mathrm{C}_{12}\right) ; 121.48$ 
$\left(\mathrm{C}_{13}\right) ; 117.02\left(\mathrm{C}_{19}\right) ; 113.40\left(\mathrm{C}_{15}\right) ; 73.35\left(\mathrm{C}_{7}\right) ; 56.53\left(\mathrm{C}_{20}\right) ; 40.83\left(\mathrm{C}_{17}\right)$. HRMS (TOF MS ES-) calculated for $\mathrm{C}_{20} \mathrm{H}_{19} \mathrm{NO}_{6}: 369.3700[\mathrm{M}+\mathrm{H}]^{+}$; found: 370.1390 .

3.4.3. 4-Allyl-2-methoxyphenyl 2-(hydroxy(2-nitrophenyl)methyl)acrylate (9)

$75 \%$ yield; FTIR: $3458 \mathrm{~cm}^{-1}(\mathrm{O}-\mathrm{H}) ; 1737 \mathrm{~cm}^{-1}(\mathrm{C}=\mathrm{O}) ; 1637 \mathrm{~cm}^{-1}(\mathrm{C}=\mathrm{C}) ; 1604 \mathrm{~cm}^{-1}(\mathrm{C}=\mathrm{C}) ; 1527$ and $1348 \mathrm{~cm}^{-1}\left(\mathrm{R}-\mathrm{NO}_{2}\right), 1033 \mathrm{~cm}^{-1}$ (C-O-C). ${ }^{1} \mathrm{H}-\mathrm{NMR} \delta(\mathrm{ppm}): 7.96-8.06$ (m, $\left.1 \mathrm{H}, \mathrm{H}-\mathrm{Ar}\right) ; 7.83(\mathrm{~d}, J=7.8 \mathrm{~Hz}$, $1 \mathrm{H}, \mathrm{H}-\mathrm{Ar}) ; 7.67$ (dd, J = 8.3, 4.6 Hz, 1H, H-Ar); 7.50 (d, J = 6.7 Hz, 1H, H-Ar); $6.93(\mathrm{~d}, J=8.6 \mathrm{~Hz}, 1 \mathrm{H}$, $\mathrm{H}-\mathrm{Ar}) ; 6.79-6.70$ (m, 2H, H-Ar); 6.61 (s, $1 \mathrm{H}, \mathrm{H}-\mathrm{C}-\mathrm{OH}) ; 6.31$ (s, $\left.1 \mathrm{H}, \mathrm{CH}_{2}=\mathrm{C}\right) ; 6.05-5.81\left(\mathrm{~m}, 2 \mathrm{H}, \mathrm{CH}=\mathrm{CH}_{2}\right.$ and $\left.\mathrm{CH}_{2}=\mathrm{C}\right) ; 5.16-5.01\left(\mathrm{~m}, 2 \mathrm{H}, \mathrm{CH}_{2}=\mathrm{CH}\right) ; 3.73\left(\mathrm{~s}, 4 \mathrm{H}, \mathrm{CH}_{3} \mathrm{OPh}\right.$ and $\left.\mathrm{HO}-\mathrm{C}\right) ; 3.36(\mathrm{~d}, J=6.7 \mathrm{~Hz}, 2 \mathrm{H}$, $\left.\mathrm{CH}_{2} \mathrm{Ph}\right) .{ }^{13} \mathrm{C}-\mathrm{NMR} \delta(\mathrm{ppm}): 164.12\left(\mathrm{C}_{10}\right) ; 150.52\left(\mathrm{C}_{16}\right) ; 148.32\left(\mathrm{C}_{5}\right) ; 140.25\left(\mathrm{C}_{9}\right) ; 139.21\left(\mathrm{C}_{14}\right) ; 137.43$ $\left(C_{6}\right) ; 136.92\left(C_{18}\right) ; 135.99\left(C_{11}\right) ; 133.50\left(C_{2}\right) ; 129.09\left(C_{3}\right) ; 128.72\left(C_{1}\right) ; 128.06\left(C_{8}\right) ; 124.67\left(C_{4}\right) ; 122.34$ $\left(\mathrm{C}_{12}\right) ; 120.65\left(\mathrm{C}_{13}\right) ; 116.18\left(\mathrm{C}_{19}\right) ; 112.61\left(\mathrm{C}_{15}\right) ; 67.88\left(\mathrm{C}_{7}\right) ; 55.72\left(\mathrm{C}_{20}\right) ; 40.04\left(\mathrm{C}_{17}\right)$. HRMS (TOF MS ES-) calculated for $\mathrm{C}_{20} \mathrm{H}_{19} \mathrm{NO}_{6}: 369.3700[\mathrm{M}+\mathrm{H}]^{+}$; found: 370.1298 .

\subsubsection{2-Isopropyl-5-methylphenyl 2-(hydroxy(4-nitrophenyl)methyl)acrylate (10)}

$80 \%$ yield; FTIR: $3485 \mathrm{~cm}^{-1}(\mathrm{O}-\mathrm{H}) ; 1732 \mathrm{~cm}^{-1}(\mathrm{C}=\mathrm{O}) ; 1606 \mathrm{~cm}^{-1}(\mathrm{C}=\mathrm{C}) ; 1523$ and $1348 \mathrm{~cm}^{-1}\left(\mathrm{R}_{-\mathrm{NO}_{2}}\right)$. ${ }^{1} \mathrm{H}-\mathrm{NMR} \delta(\mathrm{ppm}): 8.20(\mathrm{~d}, J=8.8 \mathrm{~Hz}, 2 \mathrm{H}, \mathrm{H}-\mathrm{Ar}) ; 7.63(\mathrm{~d}, J=8.6 \mathrm{~Hz}, 2 \mathrm{H}, \mathrm{H}-\mathrm{Ar}) ; 7.06(\mathrm{~d}, J=7.8 \mathrm{~Hz}, 2 \mathrm{H}$, $\mathrm{H}-\mathrm{Ar}) ; 6.78(\mathrm{~d}, J=7.3 \mathrm{~Hz}, 1 \mathrm{H}, \mathrm{H}-\mathrm{Ar}) ; 6.67(\mathrm{~s}, 1 \mathrm{H}, \mathrm{H}-\mathrm{C}-\mathrm{OH}) ; 6.12\left(\mathrm{~s}, 1 \mathrm{H}, \mathrm{CH}_{2}=\mathrm{C}\right) ; 5.75(\mathrm{~d}, J=4.8 \mathrm{~Hz}, 1 \mathrm{H}$, $\left.\mathrm{CH}_{2}=\mathrm{C}\right) ; 3.50(\mathrm{~d}, J=4.9 \mathrm{~Hz}, 1 \mathrm{H}, \mathrm{HO}-\mathrm{C}) ; 2.85$ (hept $\left.J=6.8 \mathrm{~Hz}, 1 \mathrm{H}, \mathrm{HC}-\left(\mathrm{CH}_{3}\right)_{2}\right) ; 1.95\left(\mathrm{~s}, 3 \mathrm{H}, \mathrm{H}_{3} \mathrm{C}-\mathrm{Ph}\right)$; $1.20\left(\mathrm{~d}, J=6.9 \mathrm{~Hz}, 6 \mathrm{H},\left(\mathrm{CH}_{3}\right)_{2}-\mathrm{CH}\right) .{ }^{13} \mathrm{C}-\mathrm{NMR} \delta(\mathrm{ppm}): 164.24\left(\mathrm{C}_{8}\right) ; 148.63\left(\mathrm{C}_{4}\right) ; 148.27\left(\mathrm{C}_{9}\right) ; 147.48$ $\left(\mathrm{C}_{3}\right) ; 140.93\left(\mathrm{C}_{11}\right) ; 131.01\left(\mathrm{C}_{13}\right) ; 128.23\left(\mathrm{C}_{6}\right) ; 128.16\left(\mathrm{C}_{7}\right) ; 127.56\left(\mathrm{C}_{2 / 2^{\prime}}\right) ; 126.95\left(\mathrm{C}_{14}\right) ; 124.49\left(\mathrm{C}_{12}\right) ; 123.63$ $\left(\mathrm{C}_{1 / 1^{\prime}}\right) ; 119.46\left(\mathrm{C}_{10}\right) ; 72.36\left(\mathrm{C}_{5}\right) ; 33.50\left(\mathrm{C}_{16}\right) ; 23.85\left(\mathrm{C}_{17 / 17^{\prime}}\right) ; 15.57\left(\mathrm{C}_{15}\right)$. HRMS (TOF MS ES-) calculated for $\mathrm{C}_{20} \mathrm{H}_{21} \mathrm{NO}_{5}$ : 355.1400 [M - H] $]^{-}$; found: 354.1426.

\subsubsection{2-Isopropyl-5-methylphenyl 2-(hydroxy(3-nitrophenyl)methyl)acrylate (11)}

$73 \%$ yield; FTIR: $3493 \mathrm{~cm}^{-1}(\mathrm{O}-\mathrm{H}) ; 1730 \mathrm{~cm}^{-1}(\mathrm{C}=\mathrm{O}) ; 1637 \mathrm{~cm}^{-1}(\mathrm{C}=\mathrm{C}) ; 1622 \mathrm{~cm}^{-1}(\mathrm{C}=\mathrm{C}) ; 1531$ and $1350 \mathrm{~cm}^{-1}\left(\mathrm{R}-\mathrm{NO}_{2}\right) .{ }^{1} \mathrm{H}-\mathrm{NMR} \delta$ (ppm): 8.30 (s, $\left.1 \mathrm{H}, \mathrm{H}-\mathrm{Ar}\right) ; 8.15$ (dd, J = 8.2, $\left.1.1 \mathrm{~Hz}, 1 \mathrm{H}, \mathrm{H}-\mathrm{Ar}\right) ; 7.79$ (d, J = $7.7 \mathrm{~Hz}, 1 \mathrm{H}, \mathrm{H}-\mathrm{Ar}) ; 7.53(\mathrm{t}, J=7.9 \mathrm{~Hz}, 1 \mathrm{H}, \mathrm{H}-\mathrm{Ar}) ; 7.06$ (dd, J = 7.8 Hz, 2H, H-Ar); 6.79 (s, $1 \mathrm{H}$, $\mathrm{H}-\mathrm{Ar}) ; 6.68(\mathrm{~s}, 1 \mathrm{H}, \mathrm{H}-\mathrm{C}-\mathrm{OH}) ; 6.13\left(\mathrm{~s}, 1 \mathrm{H}, \mathrm{CH}_{2}=\mathrm{C}\right) ; 5.74\left(\mathrm{~d}, J=5.2 \mathrm{~Hz}, 1 \mathrm{H}, \mathrm{CH}_{2}=\mathrm{C}\right) ; 3.36(\mathrm{~d}, J=5.6 \mathrm{~Hz}$, 1H, HO-C), 2.76-2.60 (m, 1H, HC- $\left.\left(\mathrm{CH}_{3}\right)_{2}\right) ; 1.95$ (s, 3H, $\left.\mathrm{H}_{3} \mathrm{C}-\mathrm{Ph}\right) ; 1.20$ (d, J = 6.9 Hz, 6H, $\left.\left(\mathrm{CH}_{3}\right)_{2}-\mathrm{CH}\right)$. ${ }^{13} \mathrm{C}-\mathrm{NMR} \delta(\mathrm{ppm}): 164.29\left(\mathrm{C}_{10}\right) ; 148.69\left(\mathrm{C}_{11}\right) ; 148.29\left(\mathrm{C}_{4}\right) ; 143.56\left(\mathrm{C}_{13}\right) ; 140.81\left(\mathrm{C}_{6}\right) ; 132.90\left(\mathrm{C}_{1}\right) ; 131.01$ $\left(\mathrm{C}_{2}\right) ; 129.44\left(\mathrm{C}_{15}\right) ; 128.36\left(\mathrm{C}_{8}\right) ; 128.28\left(\mathrm{C}_{9}\right) ; 126.99\left(\mathrm{C}_{16}\right) ; 124.51\left(\mathrm{C}_{5}\right) ; 122.89\left(\mathrm{C}_{3}\right) ; 121.65\left(\mathrm{C}_{14}\right) ; 119.49\left(\mathrm{C}_{12}\right)$; $72.17\left(\mathrm{C}_{7}\right) ; 33.51\left(\mathrm{C}_{17}\right) ; 23.87\left(\mathrm{C}_{18 / 18^{\prime}}\right) ; 15.60\left(\mathrm{C}_{19}\right)$. HRMS (TOF MS ES-) calculated for $\mathrm{C}_{20} \mathrm{H}_{21} \mathrm{NO}_{5}$ : $355.1400[\mathrm{M}-\mathrm{H}]^{-}$; found: 354.1154 .

\subsubsection{2-Isopropyl-5-methylphenyl 2-(hydroxy(2-nitrophenyl)methyl)acrylate (12)}

$58 \%$ yield; FTIR: $3450 \mathrm{~cm}^{-1}(\mathrm{O}-\mathrm{H}) ; 1734 \mathrm{~cm}^{-1}(\mathrm{C}=\mathrm{O}) ; 1620 \mathrm{~cm}^{-1}(\mathrm{C}=\mathrm{C}) ; 1527$ and $1348 \mathrm{~cm}^{-1}\left(\mathrm{R}_{-} \mathrm{NO}_{2}\right)$. ${ }^{1} \mathrm{H}-\mathrm{NMR} \delta$ (ppm): $7.87(\mathrm{~d}, J=7.5 \mathrm{~Hz}, 2 \mathrm{H}, \mathrm{H}-\mathrm{Ar}) ; 7.62(\mathrm{t}, J=7.5 \mathrm{~Hz}, 1 \mathrm{H}, \mathrm{H}-\mathrm{Ar}) ; 7.42(\mathrm{t}, J=7.7 \mathrm{~Hz}, 1 \mathrm{H}$, $\mathrm{H}-\mathrm{Ar}) ; 7.03$ (d, J = 7.8 Hz, 2H, H-Ar); 6.81 (s, 1H, H-Ar); 6.58 (s, 1H, H-C-OH); 6.30 (s, 1H, $\left.\mathrm{CH}_{2}=\mathrm{C}\right)$; $5.86\left(\mathrm{~s}, 1 \mathrm{H}, \mathrm{CH}_{2}=\mathrm{C}\right) ; 3.82(\mathrm{~s}, 1 \mathrm{H}, \mathrm{HO}-\mathrm{C}) ; 2.95-2.74\left(\mathrm{~m}, 1 \mathrm{H}, \mathrm{HC}-\left(\mathrm{CH}_{3}\right)_{2}\right) ; 1.96$ (s, 3H, $\left.\mathrm{H}_{3} \mathrm{C}-\mathrm{Ph}\right) ; 1.19$ (d, $\left.J=6.9 \mathrm{~Hz}, 6 \mathrm{H},\left(\mathrm{CH}_{3}\right)_{2}-\mathrm{CH}\right) .{ }^{13} \mathrm{C}-\mathrm{NMR} \delta(\mathrm{ppm}): 164.36\left(\mathrm{C}_{10}\right) ; 148.92\left(\mathrm{C}_{11}\right) ; 148.12\left(\mathrm{C}_{5}\right) ; 140.83\left(\mathrm{C}_{13}\right)$; $136.39\left(\mathrm{C}_{8}\right) ; 133.61\left(\mathrm{C}_{2}\right) ; 130.93\left(\mathrm{C}_{15}\right) ; 128.96\left(\mathrm{C}_{3}\right) ; 128.79\left(\mathrm{C}_{1}\right) ; 127.70\left(\mathrm{C}_{6}\right) ; 127.66\left(\mathrm{C}_{9}\right) ; 127.18\left(\mathrm{C}_{16}\right)$; $124.78\left(\mathrm{C}_{4}\right) ; 124.32\left(\mathrm{C}_{14}\right) ; 119.61\left(\mathrm{C}_{12}\right) ; 67.54\left(\mathrm{C}_{7}\right) ; 33.53\left(\mathrm{C}_{17}\right) ; 23.89\left(\mathrm{C}_{18 / 18^{\prime}}\right) ; 15.55\left(\mathrm{C}_{19}\right)$. HRMS (TOF MS ES-) calculated for $\mathrm{C}_{20} \mathrm{H}_{21} \mathrm{NO}_{5}: 355.1400[\mathrm{M}-\mathrm{H}]^{-}$; found: 354.1335 .

3.4.7. 5-Isopropyl-2-methylphenyl 2-(hydroxy(4-nitrophenyl)methyl)acrylate (13)

92\% yield; FTIR: $3510 \mathrm{~cm}^{-1}(\mathrm{O}-\mathrm{H}) ; 1728 \mathrm{~cm}^{-1}(\mathrm{C}=\mathrm{O}) ; 1624 \mathrm{~cm}^{-1}(\mathrm{C}=\mathrm{C}) ; 1606 \mathrm{~cm}^{-1}(\mathrm{C}=\mathrm{C}) ; 1521$ and $1348 \mathrm{~cm}^{-1}\left(\mathrm{R}-\mathrm{NO}_{2}\right) .{ }^{1} \mathrm{H}-\mathrm{NMR} \delta(\mathrm{ppm}): 8.20$ (d, J = 8.8 Hz, 2H, H-Ar); 7.63 (d, J = 8.6 Hz, 2H, H-Ar); $7.06(\mathrm{dd}, J=21.4,7.8 \mathrm{~Hz}, 2 \mathrm{H}, \mathrm{H}-\mathrm{Ar}) ; 6.78(\mathrm{~d}, J=1.2 \mathrm{~Hz}, 1 \mathrm{H}, \mathrm{H}-\mathrm{Ar}) ; 6.67$ (s, 1H, H-C-OH); 6.12 (s, 1H, 
$\left.\mathrm{CH}_{2}=\mathrm{C}\right) ; 5.75\left(\mathrm{~d}, J=4.8 \mathrm{~Hz}, 1 \mathrm{H}, \mathrm{CH}_{2}=\mathrm{C}\right) ; 3.50(\mathrm{~d}, J=4.9 \mathrm{~Hz}, 1 \mathrm{H}, \mathrm{HO}-\mathrm{C}) ; 2.85$ (hept, $J=6.8 \mathrm{~Hz}, 1 \mathrm{H}$, HC- $\left.\left(\mathrm{CH}_{3}\right)_{2}\right) ; 1.95$ (s, 3H, $\left.\mathrm{H}_{3} \mathrm{C}-\mathrm{Ph}\right) ; 1.20\left(\mathrm{~d}, J=6.9 \mathrm{~Hz}, 6 \mathrm{H},\left(\mathrm{CH}_{3}\right)_{2}-\mathrm{CH}\right) .{ }^{13} \mathrm{C}-\mathrm{NMR} \delta(\mathrm{ppm}): 164.24\left(\mathrm{C}_{8}\right)$; $148.63\left(\mathrm{C}_{4}\right) ; 148.27\left(\mathrm{C}_{9}\right) ; 147.48\left(\mathrm{C}_{3}\right) ; 140.93\left(\mathrm{C}_{11}\right) ; 131.01\left(\mathrm{C}_{13}\right) ; 128.23\left(\mathrm{C}_{6}\right) ; 128.16\left(\mathrm{C}_{7}\right) ; 127.56\left(\mathrm{C}_{2 \mathrm{e} 2^{\prime}}\right)$; $126.95\left(\mathrm{C}_{14}\right) ; 124.49\left(\mathrm{C}_{12}\right) ; 123.63\left(\mathrm{C}_{1 \mathrm{e} 1^{\prime}}\right) ; 119.46\left(\mathrm{C}_{10}\right) ; 72.36\left(\mathrm{C}_{5}\right) ; 33.50\left(\mathrm{C}_{16}\right) ; 23.85\left(\mathrm{C}_{17 \mathrm{e} 17^{\prime}}\right) ; 15.57\left(\mathrm{C}_{15}\right)$. HRMS (TOF MS ES-) calculated for $\mathrm{C}_{20} \mathrm{H}_{21} \mathrm{NO}_{5}: 355.1400[\mathrm{M}-\mathrm{H}]^{-}$; found: 354.1335.

\subsubsection{5-Isopropyl-2-methylphenyl 2-(hydroxy(3-nitrophenyl)methyl)acrylate (14)}

$63 \%$ yield; FTIR: $3450 \mathrm{~cm}^{-1}(\mathrm{O}-\mathrm{H}) ; 1735 \mathrm{~cm}^{-1}(\mathrm{C}=\mathrm{O}) ; 1637 \mathrm{~cm}^{-1}(\mathrm{C}=\mathrm{C}) ; 1602 \mathrm{~cm}^{-1}(\mathrm{C}=\mathrm{C}) ; 1531$ and $1350 \mathrm{~cm}^{-1}\left(\mathrm{R}-\mathrm{NO}_{2}\right) .{ }^{1} \mathrm{H}-\mathrm{NMR} \delta(\mathrm{ppm}): 8.30$ (s, $\left.1 \mathrm{H}, \mathrm{H}-\mathrm{Ar}\right) ; 8.14(\mathrm{~d}, J=8.2 \mathrm{~Hz}, 1 \mathrm{H}, \mathrm{H}-\mathrm{Ar}) ; 7.79$ (d, $J=7.7 \mathrm{~Hz}, 1 \mathrm{H}, \mathrm{H}-\mathrm{Ar}) ; 7.53(\mathrm{t}, J=7.9 \mathrm{~Hz}, 1 \mathrm{H}, \mathrm{H}-\mathrm{Ar}) ; 7.08$ (d, $J=7.8 \mathrm{~Hz}, 2 \mathrm{H}, \mathrm{H}-\mathrm{Ar}) ; 6.79$ (s, $1 \mathrm{H}, \mathrm{H}-\mathrm{Ar}) ; 6.68$ (s, $1 \mathrm{H}, \mathrm{H}-\mathrm{C}-\mathrm{OH}) ; 6.13\left(\mathrm{~s}, 1 \mathrm{H}, \mathrm{CH}_{2}=\mathrm{C}\right) ; 5.74\left(\mathrm{~d}, J=5.2 \mathrm{~Hz}, 1 \mathrm{H}, \mathrm{CH}_{2}=\mathrm{C}\right) ; 3.36(\mathrm{~d}, J=5.6 \mathrm{~Hz}, 1 \mathrm{H}, \mathrm{HO}-\mathrm{C})$, 2.97-2.71 (m, 1H, HC- $\left.\left(\mathrm{CH}_{3}\right)_{2}\right) ; 1.95\left(\mathrm{~s}, 3 \mathrm{H}, \mathrm{H}_{3} \mathrm{C}-\mathrm{Ph}\right) ; 1.20\left(\mathrm{~d}, J=6.9 \mathrm{~Hz}, 6 \mathrm{H},\left(\mathrm{CH}_{3}\right)_{2}-\mathrm{CH}\right) .{ }^{13} \mathrm{C}-\mathrm{NMR} \delta$ (ppm): $164.29\left(\mathrm{C}_{10}\right) ; 148.69\left(\mathrm{C}_{11}\right) ; 148.29\left(\mathrm{C}_{4}\right) ; 143.56\left(\mathrm{C}_{13}\right) ; 140.81\left(\mathrm{C}_{6}\right) ; 132.90\left(\mathrm{C}_{1}\right) ; 131.01\left(\mathrm{C}_{2}\right) ; 129.44$ $\left(C_{15}\right) ; 128.36\left(C_{8}\right) ; 128.28\left(C_{9}\right) ; 126.99\left(C_{16}\right) ; 124.51\left(C_{5}\right) ; 122.89\left(C_{3}\right) ; 121.65\left(C_{14}\right) ; 119.49\left(C_{12}\right) ; 72.17$ $\left(\mathrm{C}_{7}\right) ; 33.51\left(\mathrm{C}_{17}\right) ; 23.87\left(\mathrm{C}_{18 / 18^{\prime}}\right) ; 15.60\left(\mathrm{C}_{19}\right)$. HRMS (TOF MS ES-) calculated for $\mathrm{C}_{20} \mathrm{H}_{21} \mathrm{NO}_{5}: 355.1400$ $[\mathrm{M}-\mathrm{H}]^{-}$; found: 354.1154 .

\subsubsection{5-Isopropyl-2-methylphenyl 2-(hydroxy(2-nitrophenyl)methyl)acrylate (15)}

$72 \%$ yield; FTIR: $3489 \mathrm{~cm}^{-1}(\mathrm{O}-\mathrm{H}) ; 1734 \mathrm{~cm}^{-1}(\mathrm{C}=\mathrm{O}) ; 1624 \mathrm{~cm}^{-1}(\mathrm{C}=\mathrm{C}) ; 1527$ and $1348 \mathrm{~cm}^{-1}\left(\mathrm{R}_{-} \mathrm{NO}_{2}\right)$. ${ }^{1} \mathrm{H}-\mathrm{NMR} \delta$ (ppm): $7.86(\mathrm{~d}, J=7.5 \mathrm{~Hz}, 2 \mathrm{H}, \mathrm{H}-\mathrm{Ar}) ; 7.62(\mathrm{t}, J=7.5 \mathrm{~Hz}, 1 \mathrm{H}, \mathrm{H}-\mathrm{Ar}) ; 7.42(\mathrm{t}, J=7.7 \mathrm{~Hz}, 1 \mathrm{H}$, H-Ar); 7.03 (d, J = 7.9 Hz, 2H, H-Ar); 6.81 (s, 1H, H-Ar); 6.58 (s, 1H, H-C-OH); 6.30 (s, 1H, CH $\mathrm{CH}_{2}=\mathrm{C}$ ); $5.86\left(\mathrm{~s}, 1 \mathrm{H}, \mathrm{CH}_{2}=\mathrm{C}\right) ; 3.82(\mathrm{~s}, 1 \mathrm{H}, \mathrm{HO}-\mathrm{C}) ; 2.99-2.67\left(\mathrm{~m}, 1 \mathrm{H}, \mathrm{HC}-\left(\mathrm{CH}_{3}\right)_{2}\right) ; 1.96$ (s, 3H, $\left.\mathrm{H}_{3} \mathrm{C}-\mathrm{Ph}\right) ; 1.19$ $\left(\mathrm{d}, J=6.9 \mathrm{~Hz}, 6 \mathrm{H},\left(\mathrm{CH}_{3}\right)_{2}-\mathrm{CH}\right) .{ }^{13} \mathrm{C}-\mathrm{NMR} \delta(\mathrm{ppm}): 164.36\left(\mathrm{C}_{10}\right) ; 148.92\left(\mathrm{C}_{11}\right) ; 148.12\left(\mathrm{C}_{5}\right) ; 140.83\left(\mathrm{C}_{13}\right)$; $136.39\left(\mathrm{C}_{8}\right) ; 133.61\left(\mathrm{C}_{2}\right) ; 130.93\left(\mathrm{C}_{15}\right) ; 128.96\left(\mathrm{C}_{3}\right) ; 128.79\left(\mathrm{C}_{1}\right) ; 127.70\left(\mathrm{C}_{6}\right) ; 127.66\left(\mathrm{C}_{9}\right) ; 127.18\left(\mathrm{C}_{16}\right)$; $124.78\left(\mathrm{C}_{4}\right) ; 124.32\left(\mathrm{C}_{14}\right) ; 119.61\left(\mathrm{C}_{12}\right) ; 67.54\left(\mathrm{C}_{7}\right) ; 33.53\left(\mathrm{C}_{17}\right) ; 23.89\left(\mathrm{C}_{18 / 18^{\prime}}\right) ; 15.55\left(\mathrm{C}_{19}\right)$. HRMS (TOF MS ES) calculated for $\mathrm{C}_{20} \mathrm{H}_{21} \mathrm{NO}_{5}: 355.1400[\mathrm{M}-\mathrm{H}]^{-}$; found: 354.1516.

\subsection{Biology}

The promastigote viabilities were determined by the ability of living cells to reduce the yellow MTT (3-(4,5-dimethylthiazol-2-yl)-2,5-diphenyltetrazolium bromide, a tetrazole) to purple formazan [23]. Promastigote forms of Leishmania amazonensis (IFLA/BR/67/PH8) in the log phase of growth were incubated at $25^{\circ} \mathrm{C}$ in 96 -well cellular culture plates (TPP, Trasadingen, Switzerland) with $1 \times 10^{5}$ cells/well in $100 \mu \mathrm{L}$ Schneider's Drosophila medium supplemented with $20 \%$ of FBS in the presence or absence of different concentrations of compounds 4-15. The growth of promastigotes forms was evaluated simultaneously in the presence of Glucantime ${ }^{\circledR}$, as reference drug. After $72 \mathrm{~h}$ of incubation, $10 \mathrm{~mL}$ of a $5 \mathrm{mg} \cdot \mathrm{mL}^{-1}$ MTT solution was added. After $4 \mathrm{~h}$ of incubation at $25^{\circ} \mathrm{C}$, the formed product formazan was dissolved in $50 \mathrm{~mL}$ of sodium dodecyl sulfate (SDS) at $10 \%$ for $24 \mathrm{~h}$, and the absorbance was measured by spectrophotometry at a $545 \mathrm{~nm}$ wavelength. The percentage viability was calculated from the ratio of OD readings in the wells with compounds versus the wells without compounds $\times 100$. The concentration that inhibited $50 \%$ of growth $\left(\mathrm{IC}_{50}\right)$ was determined by regression analysis using the SPSS 8.0 software for Windows (IBM, New York, NY, USA). All experiments were performed at least three times, and each experiment was performed in triplicate [16]. Haemolytic assays $\left(\mathrm{HC}_{50}>400 \mu \mathrm{M}\right)$ showed that the 4, 7, 8, 9, 16, 17 and 3 exhibit low toxicity towards human red blood cells, unlike amphotericin $\mathrm{B}\left(\mathrm{HC}_{50}=11.61 \mu \mathrm{M}\right.$ Table 1$)$ [24].

\subsection{Conformational Analysis}

The relaxed potential energy surface scan (RPESS) was performed by taking particular care of the dihedral angles $\theta_{1}-\theta_{10}$, which are illustrated in Figure 3 . These calculations were executed by using the semi-empiric PM6 level with angle variations from $0^{\circ}$ to $360^{\circ}$ in intervals of $10^{\circ}$. Next, the minimum conformation was fully optimized by M062x//6-31+G(d,p) as the level of the calculations without any 
symmetry constraint and with all geometries modeled at a minimum of potential energy because no imaginary frequencies were found. The minima of hybrids 7 and 9 were optimized in water implicit simulations using the CPCM methodology by GAUSSIAN09L [25].

7

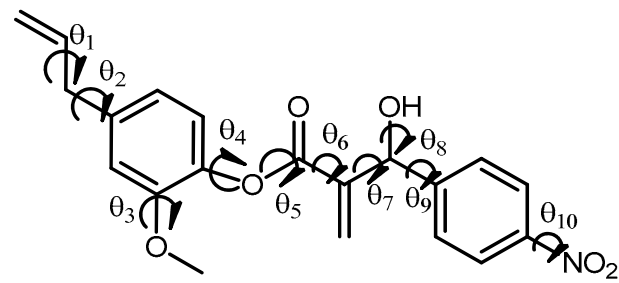

9

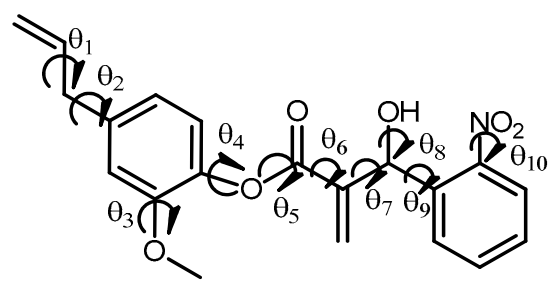

Figure 3. Computational methodology used to minimize the new hybrids 7 and 9. Optimized geometries (Cartesian coordinates) to $\mathbf{7}$ and $\mathbf{9}$ are available in the Supplementary information.

\section{Conclusions}

The nine new molecular hybrids designed in this study were synthesized in good yields in two steps from eugenol, thymol and carvacrol and presented $\mathrm{IC}_{50}$ values in the range of $22.30-4.71 \mu \mathrm{M}$ to promastigotes of Leishmania amazonensis. Besides, the most active hybrid 9 does not exhibit significant toxicity in red blood cell studies (SIrb > 84.92) which suggests the possibility of an advancement in CL and MCL treatment. The experimental studies of bioactivity and conformational DFT calculations presented here are in full agreement with our first mechanistic proposal whereby the biological activity of nitro compounds is connected to nitro group reduction that generates $\mathrm{RNO}^{-} \cdot$. Separation of the enantiomers of the new compound 9 by kinetic resolution catalyzed by lipase B from Candida antarctica [26] and performing in vivo studies will continue this present work.

Supplementary Materials: Supplementary information related to this article is available at www.mdpi.com/ $1420-3049 / 21 / 11 / 1483 /$ s1.

Acknowledgments: The authors gratefully acknowledge CNPq and CAPES for financial support; Felipe T. Martins (UFG) for the HRMS data; and PRPG-UFPB by financial support of the highly qualified native English speaking editors at American Journal Experts and the payment of publication fees of this article.

Author Contributions: Francisco José da Seixas Xavier was responsible for the chemical experiments and analyzed the data; Klinger Antonio da Franca Rodrigues was responsible for antipromastigotes experiments, Ramon Guerra de Oliveira and Claudio Gabriel Lima Junior participate in discussions during the work. Juliana da Câmara Rocha developed the study of cytotoxicity and selectivity index of compounds. Tatjana Keesen de Souza Lima directed the study of cytotoxicity and selectivity index of compounds. Marcia Rosa de Oliveira directed the study of antipromastigotes experiments; Fábio Pedrosa Lins Silva and Mário Luiz Araújo de Almeida Vasconcellos coordinate the chemical experiments and analyzed the data and had all conception of this work. They also wrote this article.

Conflicts of Interest: The authors declare no conflict of interest.

\section{References}

1. Alvar, J; Vélez, I.D.; Bern, C.; Herrero, M.; Desjeux, P.; Cano, J.; Jannin, J.; den-Boer, M. Leishmaniasis Worldwide and Global Estimates of Its Incidence. PLoS ONE 2012, 7, e35671. [CrossRef]

2. Volpinia, Â.C.; Passos, V.M.A.; Oliveira, G.C.; Romanha, A.J. PCR-RFLP to identify Leishmania (Viannia) braziliensis and L. (Leishmania) amazonensis causing American cutaneous leishmaniasis. Acta Tropica 2004, 90, 31-37. [CrossRef]

3. Leishmaniasis. Available online: http://www.who.int/leishmaniasis/en/ (accessed on 10 March 2016).

4. Rafik, L.; Rhaiem, B.; Houimel, M. Targeting Leishmania major parasite with peptides derived from a combinatorial phage display library. Acta Tropica 2016, 159, 11-19.

5. Croft, S.L.; Coombs, G.H. Leishmaniasis-current chemotherapy and recent advances in the search for novel drugs. Trends Parasitol. 2003, 19, 502-508. [CrossRef] 
6. Sangshetti, J.N.; Khan, F.A.K.; Kulkarni, A.A.; Arote, R.; Patil, R.H. Antileishmanial drug discovery: Comprehensive review of the last 10 years. RSC Adv. 2015, 5, 32376-32415. [CrossRef]

7. Lima-Junior, C.G.; Vasconcellos, M.L.A.A. Morita-Baylis-Hillman adducts: Biological activities and potentialities to the discovery of new cheaper drugs. Bioorg. Med. Chem. 2012, 20, 3954-3971. [CrossRef]

8. Basavaiah, D.; Reddy, B.S.; Badsara, S.S. Recent Contributions from the Baylis-Hillman Reaction to Organic Chemistry. Chem. Rev. 2010, 110, 5447-5674. [CrossRef]

9. Santos, M.S.; Coelho, F.; Lima-Junior, C.G.; Vasconcellos, M.L.A.A. The Morita-Baylis-Hillman Reaction: Advances and Contributions from Brazilian Chemistry. Curr. Org. Synth. 2015, 12, 830-852. [CrossRef]

10. Barbosa, T.P.; Sousa, S.C.O.; Amorim, F.M.; Rodrigues, Y.K.S.; De Assis, P.A.C.; Caldas, J.P.A.; Oliveira, M.R.; Vasconcellos, M.L.A.A. Design, synthesis and antileishmanial in vitro activity of new series of chalcones-like compounds: A molecular hybridization approach. Bioorg. Med. Chem. 2011, 19, 4250-4256. [CrossRef]

11. De Souza, R.O.M.A.; Pereira, V.L.P.; Muzitano, M.F.; Rossi-Bergmann, B.; Filho, E.B.A.; Vasconcellos, M.L.A.A. High selective leishmanicidal activity of 3-hydroxy-2-methylene-3-(4-bromophenyl) propanenitrile and analogous compounds. Eur. J. Med. Chem. 2007, 42, 99-102. [CrossRef]

12. Barbosa, T.C.; Lima, C.G., Jr.; Silva, F.P.L.; Lopes, H.M.; Figueiredo, L.R.F.; Souza, S.C.O.; Batista, G.N.; Silva, T.G.; Silva, T.M.; Oliveira, M.R.; et al. Improved synthesis of seven aromatic Baylis-Hillman adducts (BHA): Evaluation against Artemia salina Leach. and Leishmania chagasi. Eur. J. Med. Chem. 2009, 44, 1726-1730. [CrossRef]

13. Junior, C.G.L.; de Assis, P.A.C.; Silva, F.P.L.; Sousa, S.C.O.; de Andrade, N.G.; Barbosa, T.P.; Nerís, P.L.N.; Segundo, L.V.G.; Anjos, I.C.; Carvalho, G.A.U.; et al. Efficient synthesis of 16 aromatic Morita-Baylis-Hillman adducts: Biological evaluation on Leishmania amazonensis and Leishmania chagasi. Bioorg. Chem. 2010, 38, 279-284. [CrossRef]

14. Silva, F.P.L.; de Assis, P.A.C.; Lima-Junior, C.G.; de Andrade, N.G.; da Cunha, S.M.D.; Oliveira, M.R.; Vasconcellos, M.L.A.A. Synthesis, evaluation against Leishmania amazonensis and cytotoxicity assays in macrophages of sixteen new congeners Morita-Baylis-Hillman adducts. Eur. J. Med. Chem. 2011, 46, 4295-4301. [CrossRef]

15. Da Silva, W.A.V.; Rodrigues, D.C.; Oliveira, R.G.; Mendes, R.K.S.; Olegário, T.R.; Rocha, J.C.; Keesen, T.S.L.; Lima, C.G., Jr.; Vasconcellos, M.L.A.A. Synthesis and activity of novel homodimers of Morita-Baylis-Hillman adducts against Leishmania donovani: A twin drug approach. Bioorg. Med. Chem. Lett. 2016, 26, 4523-4526. [CrossRef]

16. Islamuddin, M.; Sahal, D.; Afrin, F. Apoptosis-like death in Leishmania donovani promastigotes induced by eugenol-rich oil of Syzygium aromaticum. J. Med. Microbiol. 2014, 63, 74-85. [CrossRef]

17. Morais, S.M.; Vila-Nova, N.S.; Bevilaqua, C.M.L.; Rondon, F.C.; Lobo, C.H.; Moura, A.A.A.; Sales, N.A.D.; Rodrigues, A.P.R.; Figuereido, J.R.; Campello, C.C.; et al. Thymol and eugenol derivatives as potential antileishmanial agentes. Bioorg. Med. Chem. 2014, 22, 6250-6255. [CrossRef]

18. Farias, P.A., Jr.; Rios, M.C.; Moura, T.A.; Almeida, R.P.; Alves, P.B.; Blank, A.F.; Fernandes, R.P.; Scher, M.R. Leishmanicidal activity of carvacrol-rich essential oil from Lippia sidoides Cham. Biol. Res. 2012, 45, $399-402$. [CrossRef]

19. Patterson, S.; Wyllie, S. Nitro drugs for the treatment of trypanosomatid diseases: Past, present, and future prospects. Trends Parasitol. 2014, 30, 289-298. [CrossRef]

20. Paiva, Y.G.; Souza, A.A.; Lima, C.G., Jr.; Silva, F.P.L.; Filho, E.B.A.; Vasconcelos, C.C.; Abreu, F.C.; Goulart, M.O.F.; Vasconcellos, M.L.A.A. Correlation between electrochemical and theoretical studies on the leishmanicidal activity of twelve Morita-Baylis-Hillman adducts. J. Braz. Chem. Soc. 2012, 23, 894-904. [CrossRef]

21. Paiva, Y.G.; Júnior, W.P.A.; de Souza, A.; Costa, C.O.; Silva, F.P.L.; Lima, C.G., Jr.; Vasconcellos, M.L.A.A.; Goulart, M.O.F. Electrochemical and computational studies, in protic medium, of Morita-Baylis-Hillman adducts and correlation with leishmanicidal activity. Electrochim. Acta 2014, 140, 557-563. [CrossRef]

22. Filho, E.B.A.; Ventura, E.; do Monte, S.A.; Oliveira, B.G.; Junior, C.G.L.; Rocha, G.B.; Vasconcellos, M.L.A.A. Synthesis and conformational study of a new class of highly bioactive compounds. Chem. Phys. Lett. 2007, 449, 336-340. [CrossRef]

23. Mosmann, T. Rapid colorimetric assay for cellular growth and survival: Application to proliferation and cytotoxicity assays. J. Immunol. Methods 1983, 65, 55-63. [CrossRef] 
24. Rodrigues, K.A.F.; Dias, C.N.S.; Néris, P.L.N.; Rocha, J.C.; Scotti, M.T.; Scotti, L.; Mascarenhas, S.R.; Veras, R.C.; de Medeiros, I.A.; Keesen, T.S.L.; et al. 2-Amino-thiophene derivatives present antileishmanial activity mediated by apoptosis and immunomodulation in vitro. Eur. J. Med. Chem. 2015, 106, 1-14. [CrossRef]

25. Frisch, M.J.; Trucks, G.W.; Schlegel, H.B.; Scuseria, G.E.; Robb, M.A.; Cheeseman, J.R.; Scalmani, G.; Barone, V.; Mennucci, B.; Petersson, G.A.; et al. Gaussian 09, Revision E.01; Gaussian, Inc.: Wallingford, CT, USA, 2009.

26. Xavier, F.J.S.; Neto, J.S.S.; Néris, P.L.N.; Oliveira, M.R.; Vale, J.A.; Vasconcellos, M.L.A.A. Kinetic resolution of leishmanicidal meta and para $( \pm)$-2-[Hydroxy(nitrophenyl) methyl]acrylonitrile catalyzed by CALB: In vitro evaluations of separated meta $(R),(S)$ and $(R / S)$ adducts. J. Mol. Catal. B. Enzyn. 2014, 108, 7-12. [CrossRef]

Sample Availability: Samples of the compounds are available from the authors.

(C) 2016 by the authors; licensee MDPI, Basel, Switzerland. This article is an open access article distributed under the terms and conditions of the Creative Commons Attribution (CC-BY) license (http://creativecommons.org/licenses/by/4.0/). 